\title{
IMPACTO DEL DESARROLLO URBANÍSTICO RECIENTE EN EL PAISAJE DEL CASERÍO VASCO; UNA PROPUESTA METODOLÓGICA EN LA RESERVA DE LA BIOSFERA DE URDAIBAI
}

\author{
María José Ainz Ibarrondo \\ María José González Amuchastegui \\ Departamento de Geografía, Prehistoria y Arqueología \\ Universidad del País Vasco/Euskal Herriko Uniberstsitatea \\ mj.ainz@ehu.es, mj.gonzaleza@ehu.es
}

\section{RESUMEN}

En este trabajo se desarrolla una propuesta metodológica desde la que se valora el impacto generado por el desarrollo urbanístico sobre el carácter y la integridad del paisaje en los barrios de caseríos del País Vasco, concretamente en el periodo que se extiende entre 2000 y 2012. El objetivo último de la investigación es la determinación de los factores que definen el signo y la intensidad impacto, de manera que su conocimiento permita una mejor gestión y protección del paisaje rural vasco.

Palabras clave: urbanización difusa, Reserva de la Biosfera de Urdaibai, impacto paisajístico, «Núcleo Rural», caserío.

\section{ABSTRACT}

This paper presents a methodological proposal for assessing the impact of urban sprawl on the character and integrity of the landscape in neighborhood of «caseríos» of the Basque Country, specifically in the period extending from 2000 to 2012. The ultimate goal of the research is to determine the factors that define the sign and the intensity of the impact so that their knowledge will allow better management and protection of the Basque countryside.

Keywords: urban sprawl, Urdaibai Biosphere Reserve, landscape impact, «Núcleo Rural», caserío.

Fecha de recepción: marzo 2014.

Fecha de aceptación: diciembre 2014. 


\section{INTRODUCCIÓN}

El paisaje, en cuanto que manifestación más visible de las relaciones entre la sociedad y el territorio, refleja de manera inmediata la adecuación o inconveniencia de los distintos usos y actividades humanas (Zoido, 2002). En línea con esa realidad, el objetivo de la Convención Europea del Paisaje (CEP) es de orden práctico y prospectivo, persiguiendo la definición de políticas destinadas a la protección y ordenación de los paisajes a través de la gestión de las transformaciones inducidas por la evolución social, económica y ambiental. No obstante, los procesos de degradación del paisaje pueden ser muy rápidos, de manera que a veces las políticas de protección pueden llegar tarde. Este podría ser el caso del paisaje rural vasco, muy afectado por los desarrollos urbanísticos emanados de la Legislación vasca desarrollada en los últimos 15 años.

El paisaje rural vasco adquiere la que probablemente es su expresión más valorada en los pequeños barrios de caseríos que estructuran el hábitat de la vertiente atlántica. Convertidos por los pintores costumbristas de principios del siglo XX en una imagen icónica que perdura a día de hoy, a fines de ese mismo siglo han quedado recogidos bajo una figura urbanística específica de la Legislación vasca: el Núcleo Rural, mediante la que se ha dado cauce a la presión urbanizadora que se cernía sobre ellos desde décadas atrás. Los desarrollos urbanísticos sobre estos pequeños barrios de entre 6 a 12 caseríos no se han hecho esperar; este trabajo pretende analizar y valorar el alcance de su impacto sobre los barrios de caseríos de la Reserva de la Biosfera de Urdaibai y, por extensión, en los de la vertiente vasco-atlántica, dado que todos ellos parten de una estructura común que pasa a estar regulada por la misma figura urbanística. El conocimiento de sus efectos sobre el carácter e integridad del paisaje resulta esencial para el establecimiento de las iniciativas de protección y gestión que la CEP propugna.

\section{DESARROLLO RESIDENCIAL DE LOS BARRIOS DE CASERÍOS EN LA RESERVA DE LA BIOSFERA DE URDAIBAI: EL NÚCLEO RURAL}

En el contexto territorial del País Vasco, densamente poblado con predominio de núcleos urbanos, a veces congestionados, pero siempre próximos a áreas rurales con una calidad ambiental y paisajística comparativamente muy superior, la urbanización del campo adquiere relevancia a partir de los años 1980. El fenómeno se liga no sólo a la construcción de áreas residenciales en entornos rurales, sino también a la proliferación creciente de vivienda unifamiliar aislada en suelo rústico, a imagen del poblamiento disperso propio del ámbito vascoatlántico (Ainz, 2001).

Es ese segundo vector del urban sprawl el que resulta particularmente pernicioso en cuanto que afecta al territorio en su conjunto, aparentemente a partir de impactos menores y puntuales; sin embargo, la diseminación de la vivienda unifamiliar por el territorio amenaza con la banalización de todo él. Ya en el año 1997 las Directrices de Ordenación del Territorio del País Vasco (DOT, 1997) pretendieron atajar el problema: «En el suelo no urbanizable se prohíbe el uso de la vivienda unifamiliar o bifamiliar aislada salvo en aquellos casos en que, fehacientemente, se demuestre su vinculación a la explotación de los recursos agropecuarios» (art. 10.1). No obstante, desde entonces el uso residencial sobre Suelo No Urbanizable 
(SNU) prácticamente se ha duplicado, alcanzando a día de hoy unas 3000 ha, de las que 2500 se localizan en Bizkaia (Udalplan, 2012).

Las propias DOT habían abierto la puerta hacia la consolidación y legalización del fenómeno al señalar que «la demanda de vivienda unifamiliar o bifamiliar aislada en medio rural ha de ir dirigida hacia los núcleos rurales o ámbitos clasificados y calificados urbanísticamente para acoger tal uso» (art. 10.2). Bajo el término núcleo rural se estaba aludiendo a la multitud de pequeñas agrupaciones de caseríos estructurados en torno a un mínimo espacio común sin que, en general, lleguen a constituir un plano urbano. Junto con el caserío aislado, estos pequeños barrios constituyen la forma en que se organizó el hábitat rural, particularmente en Bizkaia.

La Ley vasca 5/98 de Medidas Urgentes en Materia de Régimen de Suelo y Ordenación Urbana primero, y la Ley 2/2006 de Suelo y Urbanismo del País Vasco después convierten esa forma de hábitat en figura urbanística bajo la denominación de Núcleo Rural (NR) que se constituye, junto al Suelo Común y el Protegido, en una de las tres categorías en que puede clasificarse el Suelo No Urbanizable (Bilbao Uríbarri, 2007). Frente al resto del SNU, la especificidad del NR radica en su capacidad para acoger desarrollos residenciales no vinculados a la actividad agropecuaria. Se entiende por NR la agrupación de entre seis y veinticinco caseríos en torno a un espacio público, sobre cuyas parcelas adscritas puede ampliarse el número de viviendas hasta duplicar las existentes sin que llegue a sobrepasarse el máximo de 25.

El desarrollo urbanístico a partir de vivienda no vinculada a la explotación agraria al que los NR se han visto sometidos tras su catalogación a partir del año 1998 ha desencadenado un conjunto de impactos que, desafortunadamente, afectan seriamente el carácter paisajístico de muchos de ellos. El proyecto de Investigación «Impactos de la urbanización difusa en la Reserva de la Biosfera de Urdaibai», cuyos primeros resultados pueden consultarse en Ainz, Bilbao \& Torres (2011) y Ormaetxea et al. (2008), tenía entre sus objetivos el análisis y valoración de dicho impacto en Urdaibai, donde la presión urbanizadora y sus secuelas no han sido menores que en el conjunto de Bizkaia, incluso si allí se cuenta con una figura de protección ambiental de primer orden. El presente artículo presenta la metodología y resultados del trabajo desarrollado en materia de paisaje.

A día de hoy, los 16 municipios que integran la RBU cuentan con 68 NR que albergan 897 viviendas, sumando conjuntamente el caserío tradicional y la vivienda unifamiliar de construcción reciente (Tabla 1). Respecto al año 2000, fecha en la que el planeamiento municipal se había adaptado a la Ley 5/98, salvo en Bermeo y Gautegiz de Arteaga, los NR han registrado un incremento medio en el número de viviendas del $27 \%$, si bien en algunos municipios se alcanza ya el $50 \%$. Trasponer esos datos a la realidad supone imaginar que en un pequeño barrio de 8 caseríos, por ejemplo, se han construido en poco más de una década cuatro chalets y podrán construirse otros tantos en los próximos años. El reciente trabajo de Torres Elizburu (2014) ratifica que tras la consolidación del NR como figura urbanística, los Ayuntamientos de la vertiente atlántica del País Vasco, y muy especialmente los de Bizkaia donde como se sabe esta forma de poblamiento es más abundante que en el sector oriental, no han dudado en aplicarla a sus barrios de caseríos, asistiéndose desde entonces a un proceso sistemático de construcción de vivienda unifamiliar en NR paralelo, en términos cuantitativos, al constatado en Urdaibai. La rapidez e intensidad con que se está desarrollando el 
Tabla 1

CAPACIDAD RESIDENCIAL Y EJECUCIÓN URBANÍSTICA EN LOS NR DE URDAIBAI, 2000-2011

\begin{tabular}{|c|c|c|c|c|c|c|c|}
\hline \multirow{3}{*}{ Municipio } & \multirow{3}{*}{$\begin{array}{l}\mathrm{N}^{\mathrm{o}} \\
\mathrm{NR}\end{array}$} & \multirow{3}{*}{ Has } & \multicolumn{3}{|c|}{$\mathrm{N}^{0}$ vivienda } & \multirow{2}{*}{\multicolumn{2}{|c|}{$\begin{array}{l}\text { Incremento porcentual } \\
\text { del tamaño del núcleo }\end{array}$}} \\
\hline & & & \multirow{2}{*}{$\begin{array}{l}\text { Existente } \\
2000\end{array}$} & \multirow{2}{*}{$\begin{array}{c}\text { Máximo } \\
\text { establecido }\end{array}$} & \multirow{2}{*}{\begin{tabular}{|c|} 
Construido \\
$2000-11$
\end{tabular}} & & \\
\hline & & & & & & $2011(\%)$ & previsto $(\%)$ \\
\hline Ajangiz & 2 & 13,7 & 28 & 46 & 4 & 14 & 64 \\
\hline Arratzu & 5 & 38,8 & 65 & 99 & 0 & 0 & 52 \\
\hline \multicolumn{8}{|l|}{ *Bermeo } \\
\hline Busturia & 5 & 29,3 & 52 & 68 & 9 & 17 & 31 \\
\hline Ereño & 4 & 21,4 & 48 & 83 & 8 & 17 & 73 \\
\hline Errigoiti & 2 & 11,6 & 25 & 49 & 8 & 32 & 96 \\
\hline Forua & 4 & 14,7 & 44 & 78 & 25 & 57 & 77 \\
\hline *Gautegiz-A. & 2 & 11,8 & & 42 & & & \\
\hline Ibarrangelu & 8 & 26,5 & 69 & 123 & 12 & 17 & 78 \\
\hline Kortezubi & 6 & 25,7 & 57 & 99 & 21 & 37 & 74 \\
\hline Mendata & 7 & 42,9 & 96 & 161 & 4 & 4 & 68 \\
\hline Mundaka & 2 & 4,4 & 8 & 14 & 0 & 0 & 75 \\
\hline Murueta & 3 & 11,8 & 22 & 38 & 11 & 50 & 73 \\
\hline Muxika & 14 & 56,4 & 140 & 277 & 69 & 49 & 98 \\
\hline Nabarniz & 3 & 11,5 & 25 & 53 & 11 & 44 & 112 \\
\hline Sukarrieta & 1 & 1,3 & 4 & 6 & 2 & 50 & 50 \\
\hline RBU & 68 & 322 & 708 & 1236 & 184 & 27 & 75 \\
\hline
\end{tabular}

Fuente: Normas subsidiarias de Planeamiento; Udalplan 2012. Elaboración propia.

* En 2000, ni Bermeo ni Gautegiz de Arteaga habían aprobado la adaptación de su planeamiento municipal a la Ley 5/98, de manera que no pueden presentarse los datos completos correspondientes a dichos municipios.

proceso justifican la necesidad de establecer el signo y la intensidad del impacto paisajístico generado, a fin de valorar, antes de que sea demasiado tarde, la conveniencia o no de contar con una figura urbanística tan atípica como el NR.

El Plan Rector de Uso y Gestión de Urdaibai (PRUG, 1993) indica que los conjuntos paisajísticos valiosos son consecuencia directa de la acción del hombre, que ha dado lugar al paisaje rural equilibrado del caserío vasco atlántico. En un contexto de rápida evolución de las pautas paisajísticas tradicionales, el artículo 81 del PRUG señala que «los actos de uso del suelo y de construcción habrán de adaptarse en lo básico al ambiente en que estuvieran situados y a tal efecto, se tendrán en cuenta las siguientes normas de ordenación directa:

1) Los actos de uso del suelo tradicionales constituyen un modelo a recuperar por su adaptación y conformación del paisaje.

2) Las construcciones en lugares inmediatos o que formen parte de un grupo de edificios de carácter artístico-histórico, arqueológico, típico o tradicional habrán de armonizar con los mismos. 
3) En los lugares de paisaje abierto y natural, o en las perspectivas que ofrezcan los monumentos y los conjuntos urbanos y rurales de características histórico-artísticas, típicas o tradicionales, y en las inmediaciones de las carreteras y caminos de trayecto pintoresco, no se permitirá que la situación, masa y altura de las plantaciones, de los edificios, muros y cierres, o la instalación de otros elementos, limite el campo visual para la contemplación de aquellos, rompa la armonía del paisaje o desfigure la perspectiva de los monumentos o conjuntos».

Finalmente, el PRUG establece que las licencias urbanísticas y las autorizaciones «... podrán imponer las condiciones arquitectónicas, distancias de plantación y medidas correctoras precisas». No obstante, el PRUG carece de competencia en materia urbanística, de manera que a pesar de ciertos intentos reguladores por parte de la dirección técnica del Patronato de Urdaibai acogiéndose a las disposiciones señaladas, los impactos paisajísticos causados por el desarrollo urbanístico en los NR mejor valorados, aquellos que cuentan con buenas condiciones de centralidad o disponen de vistas a la ría de Urdaibai y el borde costero, son evidentes y no se apartan sustancialmente de los observables en el conjunto de los NR del País Vasco.

\section{METODOLOGÍA DE ANÁLISIS}

De acuerdo con el carácter prospectivo y la naturaleza del proceso que aborda este trabajo se ha adoptado una metodología de análisis próxima a la Evaluación de Impacto Ambiental ex-post, a fin de valorar la afección del desarrollo residencial sobre la calidad paisajística de los barrios de caseríos en el período 2000-2012. Se pretende que, en consonancia, con la intensidad y el signo del impacto registrado pueda replantearse la capacidad de los NR para acoger nuevos usos residenciales y, en su caso, las condiciones bajo las que deban desarrollarse. En este sentido, el Convenio Europeo del Paisaje reclama la necesidad de contemplar la componente temporal del paisaje e incorporarla en las políticas de gestión, cuyo fin último es «guiar y armonizar las transformaciones inducidas por los procesos sociales, económicos y medioambientales» (art. 1).

Este enfoque implica la comparación entre dos situaciones temporales: la calidad del paisaje previa al proceso y la actual, con el objetivo de identificar los parámetros de impacto causantes de la diferencia entre una y otra. La valoración de la calidad paisajística parte de la concepción del paisaje como una realidad física: la fisonomía de un territorio; no obstante, este trabajo intenta huir de la mera consideración de su expresión visual para atender su «carácter», resultado de la integración del sistema natural y el socio-económico. Como otros mosaicos agroforestales que son un producto acabado de las combinaciones armónicas entre sociedad y ecosistema (Nogué y Sala, 2008; Luginbühl, 2009), el paisaje de campiña generado por el caserío adquiere su máxima expresión y valoración social precisamente en estos pequeños núcleos rurales, según reconocen tanto las DOT, el PRUG de Urdaibai y, más recientemente, el Anteproyecto del Catálogo de Paisajes de la CAPV (2005), que los tipifica como «Asentamientos rurales integrados en el paisaje» remarcando su cualidad de ser zonas residenciales en suelo no urbanizable y concediéndoles un valor paisajístico de «4» sobre un máximo de 5 . 
En ese sentido, además de la afección a la calidad estética y escénica, se intentará valorar hasta qué punto se está viendo afectada la «coherencia» del paisaje, entendida como el grado de adecuación de la forma paisajística a las condiciones geoecológicas e históricas del territorio, y su «integridad» o estado de conservación del paisaje en su conjunto (Mata, 2006). A partir del trabajo de campo se han concretado una serie de parámetros que definen el impacto: la propia intensidad del proceso, el cambio en el uso del suelo, el grado de integración formal de la nueva vivienda... de cuya afección depende la calidad paisajística actual. A fin de no hacer excesivamente farragoso este apartado, cada uno de los parámetros estimados se explica y justifica en el momento en que se realiza su valoración a lo largo de los epígrafes de análisis.

No debe perderse de vista que este trabajo tiene una finalidad, además de académica, aplicada. Por tanto, desde el primer momento se planteó la oportunidad de idear un método de análisis que permitiera una comparación directa entre la calidad paisajística resultante con la previa, partiendo de una metodología y escala en la valoración del impacto próxima a la empleada en los Estudios de Impacto Ambiental, con los que la administración se encuentra familiarizada. De ahí que la evaluación se exprese en términos cuantitativos, asumiendo el riesgo que supone reducir a meros números el carácter y la dinámica de un paisaje. Tampoco se pretende que la valoración que aquí se presenta está exenta de una subjetividad inherente a cualquier análisis de paisaje, donde la percepción no sólo es inevitable, sino también inexcusable; no obstante, la selección rigurosa de los factores que definen tanto la calidad como el impacto permite una ponderación tan objetiva como pueda serlo cualquier valoración humana. La valoración final que aquí se presenta viene dada tanto por el equipo que ha formado parte de este proyecto de investigación como por la población local, cuya opinión se recabó mediante entrevistas realizadas en los NR seleccionados ${ }^{1}$.

Además del trabajo de campo y dada la componente diacrónica del estudio, ha sido preciso contar con fuentes documentales que permitieran establecer la calidad paisajística previa a los desarrollos urbanísticos derivados de la consideración legal del NR como figura urbanística. Con ese fin se han analizado, por una parte, los usos del suelo recogidos en el vuelo aéreo del año 1999 y, por otra, el Informe «Caracterización Urbanística de los Núcleos de Población Rurales en la Reserva de la Biosfera de Urdaibai» (Brusilovsky, 1996-97) que recoge una exhaustiva información cualitativa, cuantitativa y fotográfica sobre múltiples aspectos de los NR de Urdaibai en aquella fecha: estado de conservación y valor arquitectónico del caserío, elementos singulares y valor patrimonial, servicios...

1 Las entrevistas se realizaron en 2011 en todos los NR seleccionados. Los NR se dividieron en dos grupos de acuerdo con el número de viviendas totales: los que contenían ocho o menos y los que superaban ese número, estableciéndose un umbral mínimo respectivo para cada uno de ellos según el cual se realizaron 3 ó 5 entrevistas distribuidas entre la población vinculada con caseríos preexistentes o vivienda de construcción reciente según su número. Dado el pequeño tamaño de los NR, ese mínimo, que fue ampliamente superado en muchos de los barrios seleccionados y adecuadamente ponderado, garantizaba una muestra altamente representativa. Respecto al modelo de entrevista, se eligió un formato semiabierto en el que el entrevistador contaba con una batería de preguntas relativas al funcionamiento y gestión de los caseríos del barrio en 2000 y 2011, dirigida a la población vinculada al caserío, y las motivaciones que habían inducido la decisión de vivir en un NR en el caso de los nuevos residentes. Por otra parte y además de otras cuestiones que no tienen cabida en este artículo, se recabó la percepción de ambos conjuntos de población sobre el cambio paisajístico propiciado por el desarrollo urbanístico en el respectivo NR. A fin de no orientar las respuestas ni generar posibles susceptibilidades entre vecinos, en este caso se utilizó un formato más abierto y de carácter indirecto. 
Con la base metodológica descrita, el proyecto de investigación «Impactos de la urbanización difusa en Urdaibai» se desarrolló sobre una muestra de 12 núcleos rurales, un 15\% sobre los 79 con que contaba la RBU en el momento en que se inició (véase Figura 1); no obstante, la posterior desclasificación de algunos de ellos, como el de Almike (Bermeo) seleccionado y analizado en este trabajo, los ha dejado reducidos a 68. De acuerdo con el carácter proactivo de la investigación, la elección de núcleos no fue aleatoria, sino que quiso cubrir el espectro que va desde los que prácticamente han colmatado en una docena de años su capacidad urbanística, hasta aquellos otros en que aún no se ha construido nueva vivienda.

Los NR que mayor desarrollo urbanístico han conocido son aquellos que presentan mejores condiciones de accesibilidad o cuentan con vistas socialmente valoradas (Ainz, Bilbao y Torres, 2011). Dentro del primer grupo se seleccionaron Urberoaga y Landa, por su posición próxima a la BI-635, y Almike, adyacente al núcleo urbano de Bermeo. Por otra parte, se eligieron Isla, Antzoras, Ondartza y Gametxo, ubicados en las inmediaciones de la ría o el borde costero. Localizados sobre los márgenes de la cuenca de Urdaibai, con unas condicio-

Figura 1

NÚCLEOS RURALES DE URDAIBAI, SELECCIÓN DE CASOS

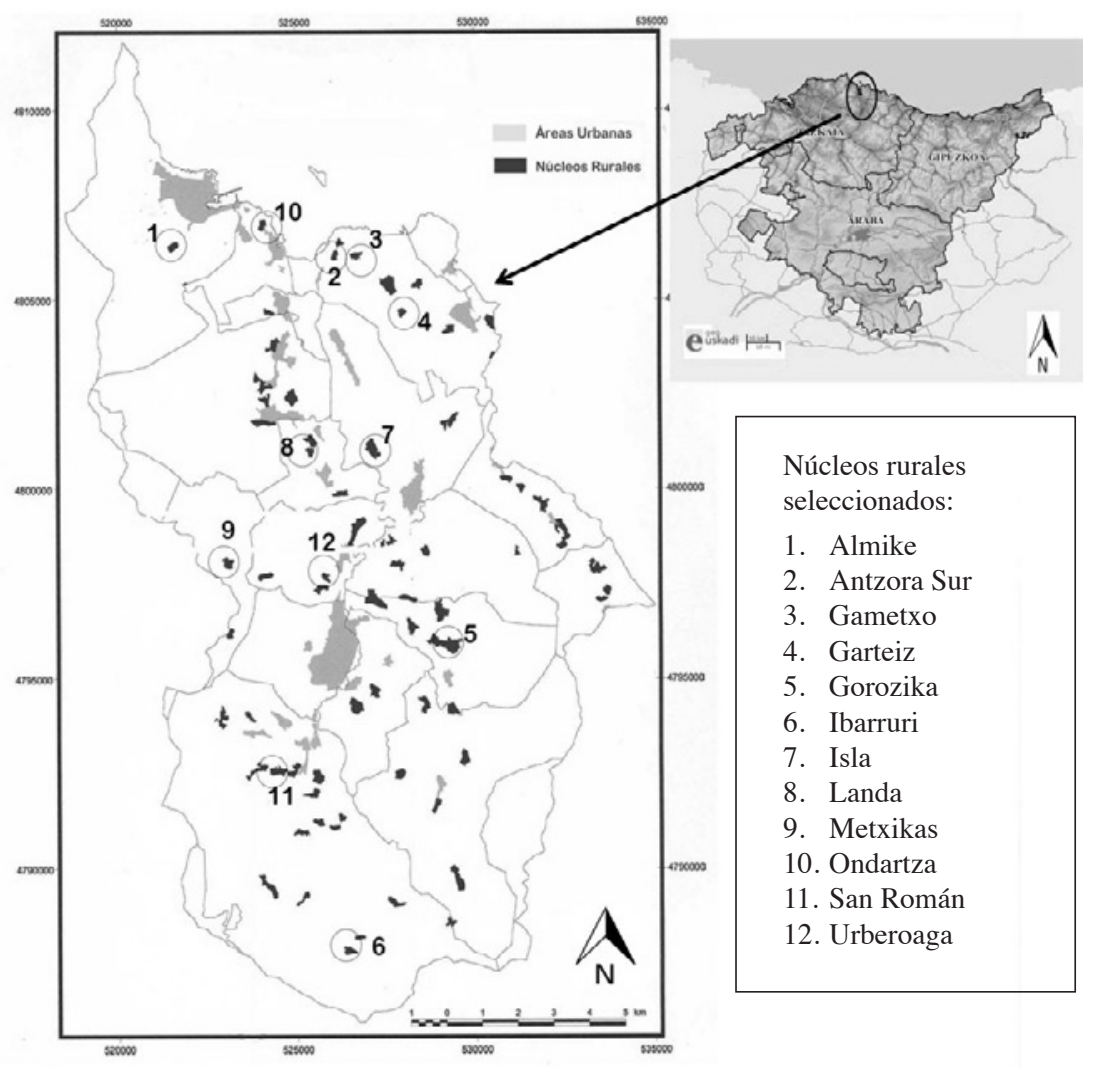

Fuente: Modificación PRUG Urdaibai, 2013. 
nes de accesibilidad peores y a pesar de su belleza sin el atractivo que confieren la costa o la ría a la radicación de segundas residencias, se han elegido seis NR; de entre ellos los que presentan mayor marginalidad locacional son Garteiz, Metxikas e Ibarruri, en una posición intermedia en términos de accesibilidad están San Román y Gorozika.

\section{ANÁLISIS Y VALORACIÓN DEL IMPACTO CAUSADO POR EL DESARROLLO URBANÍSTICO EN LOS NÚCLEOS RURALES DE URDAIBAI, 2000-2012}

A lo largo de este epígrafe se presentan en dos apartados el desarrollo y los resultados de la investigación realizada; el primero de ellos se centra en el análisis de la calidad paisajística previa al desarrollo urbanístico de los NR seleccionados, en el segundo se valora el impacto generado por dicho proceso desde el año 2000 hasta 2012 y se evalúan sus consecuencias sobre el paisaje actual. A modo de guía se incluye la tabla 2, en la que se recogen los parámetros analizados en cada fase de la investigación.

Tabla 2

ANÁLISIS DEL IMPACTO PAISAJISTICO EN LOS NR. ESQUEMA METODOLÓGICO

\begin{tabular}{|c|c|}
\hline \multicolumn{2}{|c|}{ CALIDAD PAISAJÍSTICA NR 2000} \\
\hline a) & $\begin{array}{l}\text { Calidad del Paisaje intrínseco del Núcleo Rural } \\
\text { - Condiciones fisiográficas. } \\
\text { - Usos del suelo: diversidad y dinámica } \\
\text { - Caserío preexistente: } \\
\text {-valor arquitectónico } \\
\text {-estado de conservación } \\
\text {-disposición espacial } \\
\text { - Patrimonio singular } \\
\text { - Elementos discordantes }\end{array}$ \\
\hline b) & $\begin{array}{l}\text { Calidad del Paisaje de la cuenca visible: } \\
\text { - Amplitud } \\
\text { - Usos dominantes } \\
\text { - Combinación escénica }\end{array}$ \\
\hline \multicolumn{2}{|r|}{ CALIDAD PAISAJÍSTICA DEL NÚCLEO RURAL, 2012: Calidad previa - Impacto } \\
\hline \multicolumn{2}{|r|}{ IMPACTO DEL DESARROLLO URBANÍSTICO 2000-2012 } \\
\hline a) & $\begin{array}{l}\text { Impacto bruto } \\
\text { - Intensidad } \\
\text { - Integración en el entorno: } \\
\text { - Tipología arquitectónica } \\
\text { - Artificialización de la parcela } \\
\text { - Alteración de las condiciones topográficas } \\
\text { - Integración en la estructura espacial preexistente. } \\
\text { - Cerramientos } \\
\text { - Usos suelo }\end{array}$ \\
\hline b) & $\begin{array}{l}\text { Impacto ponderado } \\
\text { - } \quad \text { Calidad paisajística previa } \\
\text { - } \quad \text { Fragilidad visual }\end{array}$ \\
\hline
\end{tabular}




\section{IV.1. La calidad paisajística de los núcleos rurales de Urdaibai en 2000}

La calidad paisajística de los Núcleos Rurales se valora en primer lugar en el que podría denominarse estado preoperacional, es decir con anterioridad al desarrollo urbanístico emanado de la Ley 5/98 y consolidado por la Ley del suelo 2/2006. La calidad paisajística de los NR se entiende que es producto, por una parte, de su paisaje intrínseco y, por otra, de la calidad de la cuenca visual que dominan. Bajo el término paisaje intrínseco se hace referencia al propio núcleo y su entorno inmediato, dado éste por el conjunto de tierras dedicadas a prados y cultivos que circundan el núcleo y habitualmente quedan delimitadas por parcelas forestales; según la estructura característica de los barrios de caseríos en el País Vasco, dicho entorno viene a coincidir con las parcelas adscritas al caserío. Respecto a la calidad de la cuenca visible desde el núcleo, no cabe duda que las «vistas» contribuyen en gran medida a la calidad paisajística total del los barrios de caseríos y, de hecho se constituyen con frecuencia en un factor de primer orden en la elección de uno u otro núcleo para radicar las nuevas viviendas; pero además, la construcción de nueva vivienda puede afectar a la cuenca visible desde el núcleo en cuanto que se ponen obstáculos que la reducen, a partir sobre todo de los cerramientos de parcelas al uso en muchas de las nuevas construcciones, según habrá ocasión de analizar.

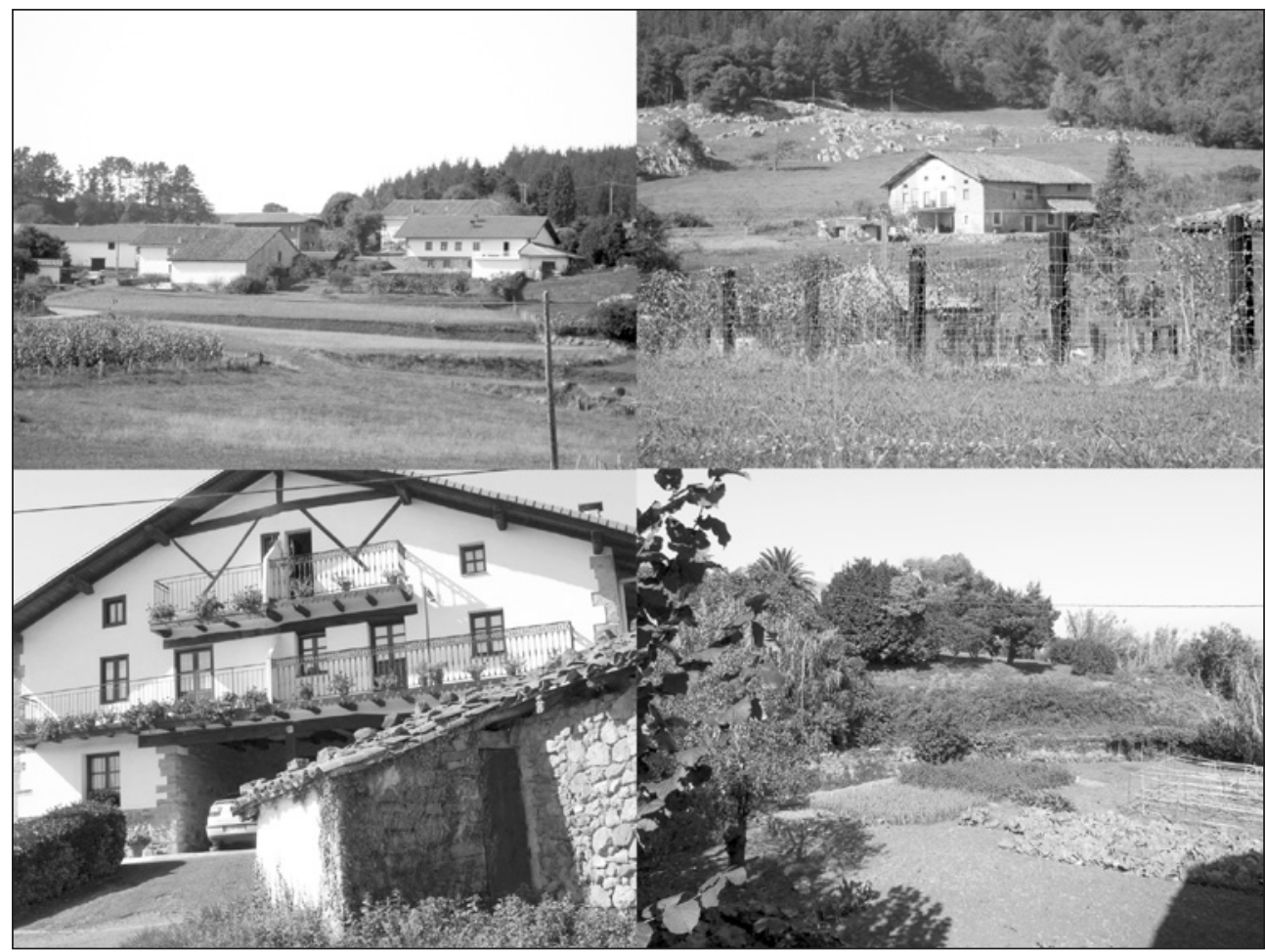


La calidad del paisaje intrínseco se valora de 1 a 10 , en tanto que la calidad de la cuenca visible desde el núcleo, las vistas, se pondera de 1 a 5 . Es decir, la calidad paisajística de un NR puede oscilar entre un mínimo de 2 y un máximo de 15 . Según se ha señalado, en esta fase de la investigación el trabajo de campo se complementa con dos fuentes documentales: la fotografía aérea (1999) y el Informe Brusilovsky (1996-97).

\section{IV.1.1. Valoración de la calidad intrínseca de los Núcleos Rurales}

La calidad del paisaje intrínseco del NR se evalúa a partir de cinco parámetros mediante los que se ha intentado aprehender no sólo su calidad estética, sino también la coherencia e integridad de su paisaje: a) condiciones fisiográficas, b) usos del suelo, c) caserío preexistente, d) patrimonio singular y e) elementos discordantes. Los parámetros a, b, c y d se han valorado según un rango que oscila entre 1 y 5; por otro lado, se valora entre 0 y 2 puntos negativos la presencia de elementos discordantes, según el grado de estridencia que introducen. La suma de los valores adjudicados a los parámetros anteriores se divide entre dos, obteniéndose un valor que oscila entre 1 y 10 y define, hasta donde un valor cuantitativo puede hacerlo, la calidad paisajística de cada NR en el momento previo al proceso (véase Tabla 3).

a) Las condiciones fisiográficas consideran la posición del núcleo en un entorno en el que la variedad y armonía de las formas topográficas lo hace más o menos atractivo. Una mayor diversidad topográfica que induce una diversificación de usos dando cabida incluso a pequeños bosquetes implica una mayor valoración, tal es el caso de Metxikas o San Román; frente a ellos Ondartza o Antzora se localizan sobre laderas en las que domina la pendiente.

Tabla 3

VALORACIÓN DEL PAISAJE INTRÍNSECO DE LOS NÚCLEOS RURALES EN 2000

\begin{tabular}{|c|c|c|c|c|c|c|}
\hline NR & a & b & c & d & e & CALIDAD INTRÍNSECA \\
\hline ALMIKE & 4 & 4 & 4 & 5 & & 8,5 \\
\hline ANTZORA SUR & 3 & 3 & 4 & 4 & & 7 \\
\hline GAMETXO & 4 & 4 & 4 & 4 & -1 & 7,5 \\
\hline GARTEIZ & 4 & 5 & 4 & 4 & & 8,5 \\
\hline GOROZIKA & 4 & 5 & 5 & 4 & & 8 \\
\hline IBARRURI & 3 & 4 & 4 & 5 & & 7,5 \\
\hline ISLA & 4 & 4 & 4 & 4 & -1 & 6 \\
\hline LANDA & 5 & 3 & 3 & 2 & -1 & 9 \\
\hline METXIKAS & 4 & 5 & 5 & 4 & & 5,5 \\
\hline ONDARTZA & 3 & 4 & 3 & 2 & -1 & 6,5 \\
\hline SAN ROMÁN & 4 & 5 & 4 & 5 & & -1 \\
\hline URBEROAGA & 5 & 4 & 3 & 2 & -1 & 8 \\
\hline
\end{tabular}

a: Condiciones morfológicas; b: Usos del suelo; c: Caserío preexistente; d: Patrimonio singular; e: Elementos discordantes.

Fuente: elaboración propia.

b) Los usos del suelo presentes en las parcelas adscritas a los caseríos que integran el NR y se localizan en el entorno inmediato de éstos, determinan en gran medida la calidad del paisaje en el entorno inmediato al núcleo en sí. La diversidad de usos y vitalidad de los 
mismos han sido los aspectos considerados determinantes a la hora de valorar este parámetro fundamental, ya que tal diversidad obedece al dinamismo que el caserío, tomado como explotación agraria, manifiesta. El abandono de la actividad agraria produce además de la homogenización de usos, el abandono de parcelas de carácter marginal, el descuido de los deslindes, sistemas de drenaje... todo lo cual contribuye a la merma de la calidad paisajística intrínseca del NR. Aquellos con unas condiciones topográficas desfavorables a la actividad agropecuaria, dadas sobre todo por niveles de pendiente elevados, fueron los primeros en manifestar dinámicas de abandono: casos de Ondartza o Antzora. Por el contrario, Gorozika y Metxikas con explotaciones mejor dimensionados en sectores a su vez más favorables desde el punto de vista agroecológico alcanzan los valores más altos.

c) La calidad del caserío preexistente se establece mediante tres indicadores: valor arquitectónico, estado de conservación y distribución espacial y cuya valoración se ha realizado a partir del informe Brusilovsky (1996-97)

- Valor arquitectónico. El caserío vasco puede definirse como una casa-bloque de labranza, con estructura de madera, muros de piedra y tejado a dos aguas normal a la fachada principal. Su mayor o menor valor tiene que ver ante todo con la armonía de sus proporciones si bien, a pesar de su sencillez y su carácter eminentemente funcional: «Muy pocos caseríos se encuentran donde no sea dable ver algún intento de adornar, ya la puerta de entrada [...] ya el maderamen a la vista [...] ya el escudo de armas o una clave decorada etc.» (Baeschlim, 1929: 22).

- Estado de conservación. El caserío se remonta al siglo XV, los últimos se levantaron a finales del XIX y muy excepcionalmente en las inicios del XX. Una vez que el caserío, en cuanto que explotación agraria, comienza a perder su funcionalidad económica fueron muchos los que se abandonaron. Sin embargo, la mejora del transporte y la valoración social del espacio en que se ubica lo puso de moda, generalizándose a partir de los años 1980 la rehabilitación de caseríos. Es decir, que su estado de conservación era por regla general bueno en los NR analizados, sin que ello signifique que los arreglos fueran siempre adecuados.

- Disposición espacial. Por norma general, en los NR no puede hablarse de plano urbano; el caserío no se organiza formando calles, pero sí puede hacerlo en torno a pequeños espacios comunes, de forma que en algunos casos se proyecta una imagen de mayor estructuración, como en Ibarruri o Garteiz, frente a Landa u Ondartza.

d) De acuerdo con su entidad y función territorial, los NR pueden contar con algún tipo de patrimonio singular dado por ermitas, plazuelas de encuentro, frontones, áreas acondicionadas para el deporte rural, fuentes... que además de enriquecer el núcleo, lo cohesionan espacial y socialmente, todo ello con clara traslación en su calidad paisajística. En este sentido, la diferencia entre Ibarruri o Almike frente a otros como Urberoaga o Landa resulta muy evidente.

e) Por último, se considera la existencia de ciertos elementos discordantes que puedan generar estridencias sobre la armonía del núcleo; caso de la cantera de Urberoaga, las carreteras que seccionan los núcleos de Ondartza, Isla... 


\section{IV.1.2. Valoración de la calidad paisajística de la cuenca visual}

Como ya se ha indicado, a la calidad paisajística intrínseca de cada NR seleccionado se le suma la de la cuenca visible desde el núcleo, que se valora atendiendo a tres parámetros: a) amplitud, b) tipología de usos dominantes y c) combinación escénica. Evaluados de 1 a 5 según los criterios que se exponen a continuación, su media representa la calidad paisajística de la cuenca visual.

a) La amplitud hace referencia al tamaño de la cuenca apreciable desde el NR, calculada mediante un modelo digital del terreno. De acuerdo con ese parámetro se han otorgado valores desde las cuencas inferiores a 250ha, caso de Ibarruri, hasta las superiores a 2500ha, entre las que se encuentran las correspondientes a los NR con vistas al mar (Ormaetxea et al. 2008).

Tabla 4

CALIDAD PAISAJISTICA DE LA CUENCA VISIBLE DESDE LOS NÚCLEOS RURALES

\begin{tabular}{|c|c|c|c|c|}
\hline NR & Amplitud & Usos dominantes & $\begin{array}{c}\text { Combinación } \\
\text { escénica }\end{array}$ & $\begin{array}{c}\text { Calidad } \\
\text { cuenca }\end{array}$ \\
\hline ALMIKE & 5 & 3,3 & 3 & 3,8 \\
\hline ANTZORASUR & 5 & 5 & 5 & 5 \\
\hline GAMETXO & 3 & 4,2 & 4 & 3,7 \\
\hline GARTEIZ & 2 & 3,7 & 4 & 3,2 \\
\hline GOROZIKA & 4 & 3 & 4 & 3,7 \\
\hline IBARRURI & 1 & 2 & 3 & 2 \\
\hline ISLA & 4 & 4,5 & 4 & 4,2 \\
\hline LANDA & 3 & 4 & 3 & 3,3 \\
\hline METXIKAS & 3 & 1,7 & 3 & 2,6 \\
\hline ONDARTZAPE & 5 & 4,5 & 5 & 4,8 \\
\hline SAN ROMÁN & 5 & 2,7 & 3 & 3,6 \\
\hline URBEROAGA & 2 & 2,3 & 3 & 2,4 \\
\hline
\end{tabular}

Fuente: elaboración propia.

b) Los usos del suelo contenidos en las respectivas cuencas visuales se han dividido en tres grandes tipos: las áreas con vegetación autóctona - encinares cantábricos y bosques mixtos - , la campiña atlántica - praderas, huertas y caseríos - y el uso forestal intensivo - pinares y eucaliptales - , calculándose el porcentaje representado por cada uno de ellos. Se han valorado negativamente las plantaciones, de manera que a mayor presencia se otorga menor valor; debe considerarse que se trata de formaciones monoespecíficas que en su conjunto ocupan la mitad del suelo de la Reserva y generan manchas monótonas y masivas. Su valor paisajístico menor se reduce aún más si se suman los efectos visuales que genera el método habitual de explotación: la tala a matarrasa.

El elevado grado de naturalidad comparativo que presentan las áreas con vegetación autóctona, así como las de campiña, apreciadas no ya sólo por su valor estético sino también emocional, generan una valoración positiva para ambos conjuntos, de manera que a mayor porcentaje de ocupación en la cuenca visual se obtienen valores progresivamente elevados. 
Por último, resta el uso denominado «borde costero» cuya presencia indica vistas al mar, aspecto éste que lo convierte en un factor diferencial que lleva a considerar únicamente su ausencia o presencia, calificada entre 0 y 1,5. Se han desestimado aquellos casos en que el porcentaje presenta valores muy bajos y lejanía del propio núcleo, de manera que la vista marina resulta inapreciable, casos de San Román, Landa y Garteiz.

c) La combinación escénica valora la amenidad de la cuenca visual de acuerdo con la distribución de los usos, su proximidad o lejanía y la diversidad topográfica.

\section{IV.1.3. La calidad paisajística de los Núcleos Rurales en 2000, análisis de resultados}

El valor acumulado por la calidad del paisaje intrínseco y el de la cuenca visible representa la calidad paisajística de los NR en el momento previo a su desarrollo urbanístico de los últimos 12 años (véase Figura 3). La primera apreciación respecto a los valores así obtenidos debe ser la buena calidad media que en su conjunto presentaban los NR analizados: La mitad de ellos obtienen un valor superior a 11, siendo 9 el mínimo, dentro de un rango que puede oscilar entre 2 y 15 . No obstante, el análisis fino ajusta esa primera evaluación.

\section{Figura 3}

CALIDAD PAISAJISTIICA DE LOS NÚCLEOS RURALES DE URDAIBAI EN 2000

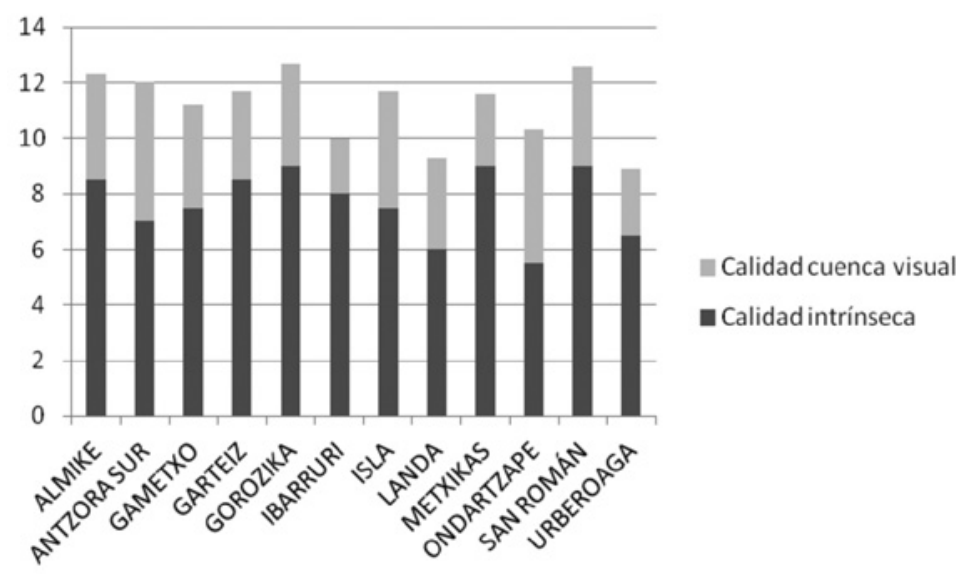

Fuente: elaboración propia.

Los valores más elevados, por encima de 12, corresponden a Gorozika, San Román y Almike; no en vano son éstos junto con Metxikas los NR mayores por el volumen de caseríos que acogen, dato que tiene que ver con el tamaño y calidad de las tierras sobre las que se instalan y que deriva en una mejor estructuración en cuanto que nodos de mayor significado territorial. Pero además, en estos núcleos se detectan los caseríos mayores por el volumen de las tierras que gestionan y si bien no todos se mantenían funcionales en cuanto que explotaciones agrarias, sí lo hacía alguno de ellos que por lo general explotaba además de sus tierras las de caseríos adyacentes. Este hecho, que también tiene lugar en Garteiz a pesar de su menor tamaño, repercutía directamente en la coherencia paisajística del núcleo. 
No obstante, ninguno de los núcleos que presentaban una mejor calidad en su paisaje intrínseco disponía de un valor paralelo en lo que respecta a la calidad de la cuenca visible, una circunstancia que no es casual. Antzora, Isla y Ondartza disponen de las cuencas visuales de mayor calidad, dada en buena medida por la presencia del mar y la ría de Urdaibai. Sin embargo, su calidad intrínseca es media para los dos primeros y la más baja del conjunto para Ondartza. Son barrios de caseríos localizados en laderas y, en consecuencia, con peores recursos productivos; en Ondartza o Antzora siempre se compaginó el trabajo en el caserío con el de la mar. Todo ello indujo abandonos de la actividad agraria tempranos y la consiguiente pérdida paisajística asociada, pero además son precisamente estos núcleos los afectados por una urbanización temprana.

De acuerdo con la encuesta realizada, los barrios de caseríos con vistas al mar registraron procesos de urbanización anteriores a la consideración del NR como figura urbanística. Su valoración en las décadas de 1970-80 para la instalación de segundas residencias, asociadas a vivienda de nueva planta pero también a la rehabilitación de caseríos, reforzó el proceso de abandono señalado anteriormente al introducir la expectativa de venta entre los propietarios de tierra. Por distintas razones, en Landa y Urberoaga se produjo un proceso de pérdida paisajística también temprana. En el primero de ellos, que nunca se constituyó en un barrio de caseríos propiamente dicho puesto que no hubo un espacio común que lo cohesionara como tal, la excelente accesibilidad atrajo la instalación de nueva vivienda con anterioridad al proceso que aquí se analiza. En Urberoaga, donde se obtiene el valor más bajo del conjunto, al hecho de no disponer prácticamente de cuenca visual externa, se suma la presencia de una cantera en el propio barrio que contribuyó a mixtificar su carácter.

En definitiva, en el momento en que los barrios de caseríos de Urdaibai pasan a considerarse figura urbanística no todos ellos disponían de la calidad óptima que desde multitud de instancias y documentos se les presuponía y ello relacionado, en buena medida, con procesos de urbanización tempranos, incluso si fueron mucho más tenues que el que se desarrollará en estos primeros años del siglo XXI.

\section{IV.2. La calidad paisajística en los núcleos rurales de Urdaibai en 2012}

La comparación entre la calidad previa a los desarrollos urbanísticos derivados de la consideración del NR como figura urbanística con su calidad actual ha permitido identificar los parámetros responsables de la alteración paisajística en los barrios de caseríos. El valor del impacto, que puede oscilar entre 0 y 7,5 puntos según el razonamiento que se expone más adelante, equivale a la pérdida paisajística causada por la urbanización entre 2000 y 2012; una pérdida que como habrá ocasión de ver ha sido sustancial.

\section{IV.2.1. Valoración del impacto paisajístico generado por los desarrollos urbanísticos de los NR de Urdaibai, 2000-2012}

Se han reconocido cuatro parámetros generadores de impacto; los tres primeros operan sobre la integridad y coherencia del paisaje: a) el volumen de nueva vivienda construida respecto al número de caseríos existentes, b) su integración en el entorno y c) la tipología de los cerramientos empleados en las parcelas que la acogen; el cuarto, d) usos del suelo, determina 
el carácter del paisaje actual. Valorados todos ellos de 0 a 5, desde una incidencia paisajística nula a otra máxima, el valor bruto del impacto medio obtenido es ponderado según dos condiciones del núcleo: su calidad paisajística previa y su fragilidad visual (véase Tabla 5).

a) La intensidad del proceso urbanizador en el NR se entiende como la relación entre el número de caseríos y el de nuevas viviendas construidas. Es preciso señalar que en este trabajo no se considera el número de viviendas alojadas en cada caserío, que en ocasiones puede ser de dos o incluso tres, sino el de edificios dado que, en términos visuales, es ése el parámetro observable. No obstante, en algunos casos el planeamiento municipal ha considerado el total de viviendas alojadas en el conjunto de caseríos para determinar el número de nuevas construcciones, de forma que éstas pueden sobrepasar el número de caseríos.

Es cierto que en términos absolutos el volumen de nuevas viviendas en los núcleos rurales de Urdaibai, o del País Vasco en general, puede parecer casi insignificante; en San Román, el NR con mayor desarrollo urbanístico absoluto se han construido 9 viviendas unifamiliares, 7 en Landa e Isla, 3 en Gorozika y Antzora Sur... No obstante, por relación al tamaño de los propios núcleos esos números son suficientes para que la alteración de las condiciones paisajísticas previas resulte muy evidente, al punto que aquellos NR donde el número de nueva vivienda se aproxima al de caseríos tienden a parecerse más a urbanizaciones suburbanas que al núcleo rural que constituían hace apenas una docena de años.

Tabla 5

PARÁMETROS QUE DEFINEN EL IMPACTO DE LOS DESARROLLOS URBANÍSTICOS

\begin{tabular}{|c|c|c|c|c|c|c|}
\hline & a & b & c & d & Impacto bruto & Impacto ponderado \\
\hline ALMIKE & 5 & 2,7 & 4 & 3 & 3,7 & 5,2 \\
\hline ANTZORA SUR & 3 & 5 & 5 & 4 & 4,3 & 6,1 \\
\hline GAMETXO & 4 & 2,5 & 1 & 2 & 2,4 & 3,4 \\
\hline GARTEIZ & 0 & 0 & 0 & 1 & 0,2 & 0,3 \\
\hline GOROZIKA & 1 & 1,8 & 0 & 1 & 0,9 & 1,3 \\
\hline IBARRURI & 2 & 1 & 1 & 1 & 1,3 & 1,7 \\
\hline ISLA & 4 & 3,3 & 5 & 4 & 4,1 & 5,7 \\
\hline LANDA & 5 & 4 & 5 & 5 & 4,7 & 6,1 \\
\hline METXIKAS & 0 & 0 & 0 & 1 & 0,2 & 0,3 \\
\hline ONDARTZAPE & 5 & 4,5 & 5 & 4 & 4,6 & 6 \\
\hline SAN ROMÁN & 4 & 1,8 & 2 & 2 & 2,4 & 3,4 \\
\hline URBEROAGA & 4 & 3,5 & 4 & 4 & 3,9 & 4,3 \\
\hline
\end{tabular}

a) Intensidad; b) Integración en el entorno; c) Cerramientos; d) Usos de suelo Fuente: elaboración propia.

b) La integración en el entorno que presentan las construcciones nuevas se mide a partir del análisis de cuatro elementos:

- La tipología arquitectónica de la vivienda nueva presenta, en general, una clara querencia hacia la imitación del caserío, circunstancia que no implica necesariamente una buena integración. Con frecuencia, tamaños, colores, materiales... aportan un grado 
de artificialidad del que una tipología menos ocupada en parecer lo que no es y más volcada en fundirse con su paisaje inmediato quizá carecería.

- La artificialización de la parcela tiene que ver con la presencia de explanadas asfaltadas, aceras, piscinas... que restan naturalidad al núcleo, aproximándolo a la urbanización suburbana.

- La alteración de las condiciones topográficas preexistentes es frecuente cuando la vivienda se instala en parcelas con pendientes que exigen ese tipo de actuación; una circunstancia habitual dada la realidad topográfica tanto de la cuenca de Urdaibai como de la vertiente vasco-atlántica en general. Se producen así aterrazamientos con fuertes rupturas de pendiente de gran impacto visual, casos de Antzora, Ondartza...

- La integración en la estructura preexistente hace referencia a la disposición de la vivienda de nueva planta respecto a la estructura espacial que presenta el caserío. En este sentido, la integración tiende a ser deficiente en prácticamente todos los casos, ya que al decidirse desde el planeamiento municipal las parcelas susceptibles de acoger nueva vivienda en cada núcleo no se atiende a ese criterio; únicamente se observa que de acuerdo con el parcelario existente dichas parcelas cuenten con acceso directo a los viales actuales, sin que por normativa sea posible la construcción de otros nuevos o la reorganización del parcelario. El caso de Urberoaga es paradigmático, con los chalets ocupando las tierras centrales del núcleo, las más profundas y llanas, los antiguos caseríos quedan marginados del que fuera su barrio. El hecho de que la nueva vivienda se disponga junto a los viales desdibuja por completo los núcleos.

El valor medio de estos cuatro aspectos determina el grado de integración de la nueva vivienda en el NR. En Antzora, Ondartza y Landa la falta de integración con el entorno es máxima, en tanto que en San Román a pesar del comparativamente importante volumen de nueva vivienda construida en los últimos años, la integración de éstas en su entorno próximo es mayor; un hecho vinculado probablemente al origen local de los propietarios, que da lugar a edificaciones más discretas y a un menor acondicionamiento de la parcela, que en parte puede incluso seguir dedicada a su uso anterior.

c) Los cerramientos de las parcelas urbanizadas constituyen un factor de impacto de primer orden que ha llevado a considerarlo separadamente del parámetro anterior. Cada nuevo propietario que opta por cercar la parcela con vallados altos, en general a base de enrejados combinados con seto, introduce en el núcleo entre 200 y 300 m lineales de auténtico muro verde (veáse Figura 4). Esta circunstancia unida a la ubicación de las parcelas junto a los caminos de acceso hace que a pie de núcleo se pierda la perspectiva del conjunto, además de la integridad del paisaje. El caserío no cierra sus parcelas, a lo sumo se utiliza el alambre de espino para facilitar el manejo del ganado, pero es éste un cerramiento sin incidencia visual práctica. Cuando el propietario presenta algún tipo de vínculo con el núcleo es frecuentemente que se decida por los cercados blandos: Gorozika, San Román... frente a Antzora, Landa o Urberuaga.

Por otra parte, el impacto que generan los cerramientos puede trascender el propio núcleo rural caso de afectar a la cuenca visual observable desde aquel. De acuerdo con su localización y dimensiones, los cerramiento restan las tan apreciadas vistas al transeúnte que pueda 


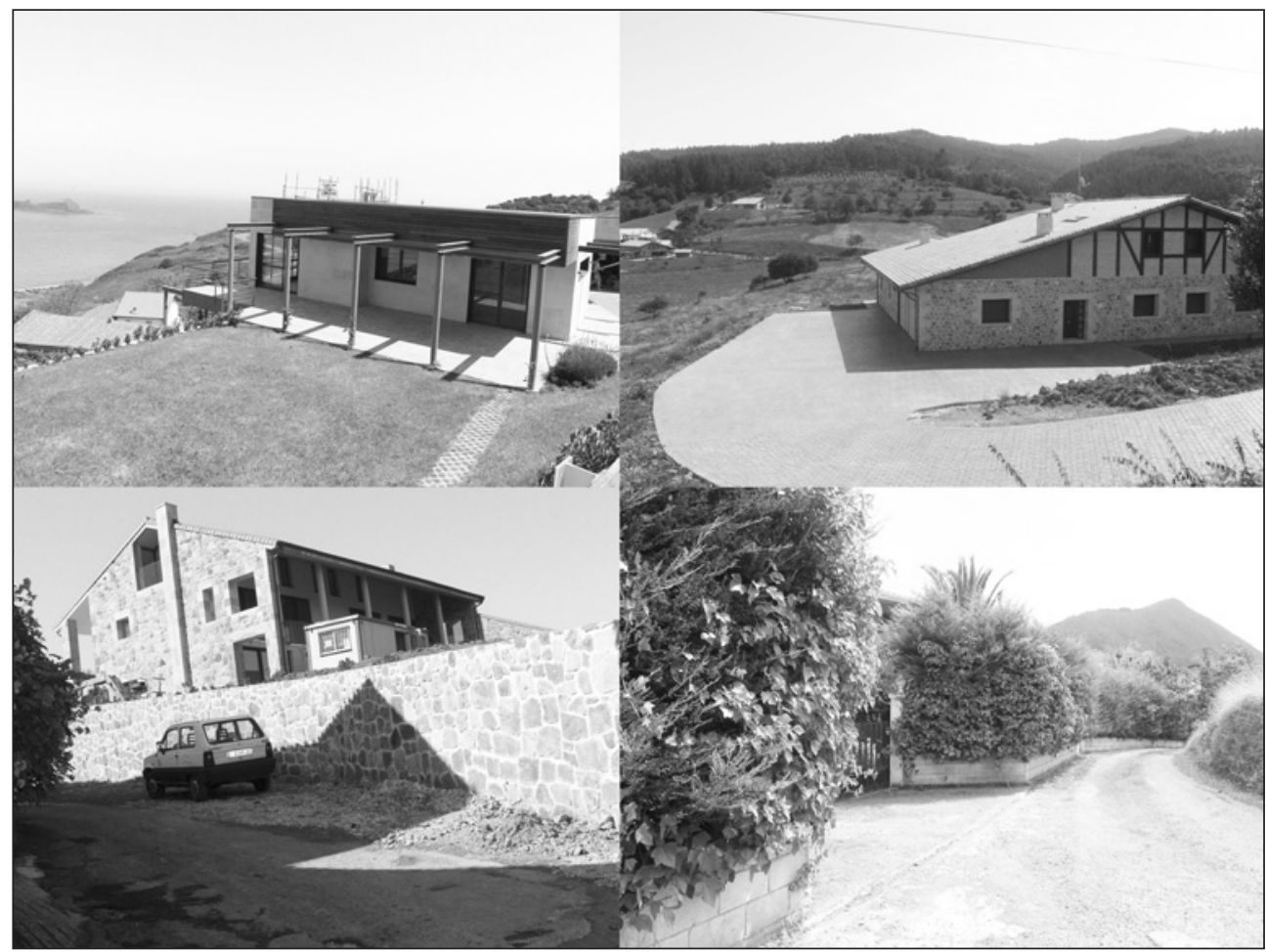

utilizar esos viales; en un tramo de las carreteras de Ondartza o Antzora se dejará de apreciar la vista marina para circular junto a un seto de considerables dimensiones.

d) Los usos del suelo, de los que en gran medida depende el que el carácter del paisaje del NR responda a lo que se supone que es: un núcleo rural constituido por un conjunto de caseríos y las tierras que tienen adscritas y gestionan en cuanto que explotaciones agrarias, se valoran por comparación con los usos existentes en el momento previo a su desarrollo urbanístico. El mero hecho de que se construya nueva vivienda en un NR ya supone un cambio de uso en las parcelas que la acogen. De acuerdo con lo establecido por la Ley, el desarrollo urbanístico del NR debe respetar el parcelario existente, de manera que cuando se construye una vivienda se sustrae del uso agrario no ya el espacio que ocupa la casa y al que podría añadirse una superficie mayor o menor de jardín, sino que es toda la parcela la que se segrega de la explotación agraria, del caserío.

El tamaño medio de los NR, precisamente constituidos por el conjunto de parcelas que forman el recurso productivo tierra de los caseríos que albergan, suele situarse entre las 5 y 15ha de manera que la construcción de, por ejemplo, 5 nuevas viviendas sobre parcelas que oscilan entre $2.500-5000 \mathrm{~m}^{2}$ no resulta baladí en términos visuales y, menos aún, en términos de viabilidad agraria. En este sentido, debe considerarse que el caserío es una explotación 
con una base territorial de 2 a 5ha, acercándose más al límite inferior que al superior; una merma de tierra insignificante en otro contexto aquí no lo es.

De acuerdo con la encuesta realizada, existe una clara correlación entre el desarrollo urbanístico y el abandono de la actividad agraria en el período analizado. Por supuesto, dado el fuerte envejecimiento de la población agraria, las dificultades por las que atraviesa el sector... no parece lícito achacar únicamente al desarrollo urbanístico de los NR la merma de la actividad acaecida en estos últimos años. No obstante, su incidencia es innegable en la aceleración del proceso. La venta de una parcela, dado el elevado precio que puede llegar a alcanzar en un entorno altamente valorado, permite anticipar el cese de la actividad al propietario de la explotación.

Probablemente ésta es la causa que explica el notable deterioro paisajístico que registran aquellos NR con procesos urbanísticos más antiguos en lo que a la vitalidad de los usos agrarios y marginalización de parcelas respecta, frente a otros como Metxikas o Garteiz donde un mayor dinamismo agropecuario resulta evidente. No obstante, incluso en éstos es observable cierta pérdida en el período estudiado. En este sentido y de acuerdo con la información recabada mediante encuesta, mientras la expectativa de posibles ventas de parcelas clasificadas por el planeamiento vigente para acoger vivienda se mantenga, la probabilidad de que puedan formar parte de explotaciones dinámicas parece remota en cualquiera de los NR estudiados, incluso en aquellos que por el momento no han conocido desarrollo urbanístico alguno.

El valor bruto del impacto sobre la calidad paisajística de cada NR está dado por la media de los cuatro parámetros analizados; este valor, según se ha indicado se pondera de acuerdo con dos factores: la calidad paisajística previa del núcleo y su fragilidad visual. Respecto al primero de ellos, se entiende que impactos de igual intensidad generan una pérdida proporcionalmente mayor en un núcleo de gran calidad paisajística. El segundo factor que pondera el impacto es la posibilidad de que sea visualizado por un número mayor o menor de personas, de acuerdo con su situación topográfica y su localización en vías de comunicación de más o menos tránsito.

Tabla 6

MATRIZ DE PONDERACIÓN DE IMPACTO

\begin{tabular}{|c|c|c|c|}
\cline { 2 - 4 } \multicolumn{1}{c|}{} & \multicolumn{3}{c|}{ Calidad paisajística NR 2000 } \\
\hline Fragilidad visual & ALTA $(12-13,5)$ & BUENA $(10,6-12)$ & MEDIA(9-10,5) \\
\hline ALTA $(\geq 4)$ & 1,5 & 1,4 & 1,3 \\
\hline MEDIA $(\geq 2<4)$ & 1,4 & 1,3 & 1,2 \\
\hline BAJA $(<2)$ & 1,3 & 1,2 & 1,1 \\
\hline
\end{tabular}

El índice de ponderación oscila en una escala que va 1,1 a 1,5. Dado que en cualquiera de los NR analizados se parte de una calidad paisajística media, se estima que aunque ésta se combine con una baja fragilidad visual el valor bruto del impacto debe incrementarse al menos en un $10 \%$. A partir de ese valor, puede darse un incremento máximo del $50 \%$ en aquellos NR en que concurren una calidad paisajística previa y una fragilidad visual máximas, de manera que el valor del impacto ponderado oscila entre 0 y 7,5 . 
Desde un impacto prácticamente inexistente en Metxikas y Garteiz, donde el proceso aún no se ha iniciado, si bien se cuenta con esa expectativa, los mayores valores se alcanzan en Antzora, Ondartza, Isla y Landa. Próximos al borde costero o la ría, son aquellos que disfrutan de las vistas al mar y al estuario más codiciadas de la Reserva y cuyo desarrollo urbanístico, salvo en el caso de Landa de carácter mixto, está sobre todo relacionado con la segunda residencia. En el resto de núcleos, donde la nueva vivienda tiende a ser de carácter habitual, el valor del impacto es algo más reducido aunque en aquellos con mejores condiciones de accesibilidad, como Almike y Urberoaga, también se registran valores considerables.

\section{IV.2.2. La calidad del paisaje en los NR de Urdaibai en 2012. Análisis de resultados}

El objetivo último de este trabajo es prospectivo; la comparativa entre la calidad paisajística previa en los NR analizados y su calidad actual presenta la virtualidad de mensurar, prácticamente a golpe de vista, el impacto generado por el desarrollo urbanístico en el corto plazo de tiempo analizado pero también el nivel que puede alcanzar en los próximos años. Según se indicaba, la medición de los parámetros que definen el impacto parte del análisis de la calidad paisajística en los barrios de caseríos en el momento previo y el momento actual, transcurridos 12 años tras su consideración en la legislación vasca como figura urbanística, de forma que restando al valor de la calidad paisajística en 2000 el del impacto generado por su desarrollo urbanístico se obtiene la calidad paisajística actual.

Se ha partido de la siguiente premisa: el desarrollo urbanístico máximo de un NR podría generar un impacto capaz de reducir una calidad paisajística también máxima a la mitad; es decir, que según la metodología y criterios propuestos en este trabajo pasaría de 15 a 7,5. Tal premisa se asienta en el límite legal vigente según el cual el número máximo de nuevas viviendas permitidas no puede superar al de las preexistentes, estableciéndose un techo de

Figura 5

CALIDAD PAISAJÍSTICA DE LOS NR DE URDAIBAI EN 2000 Y 2012

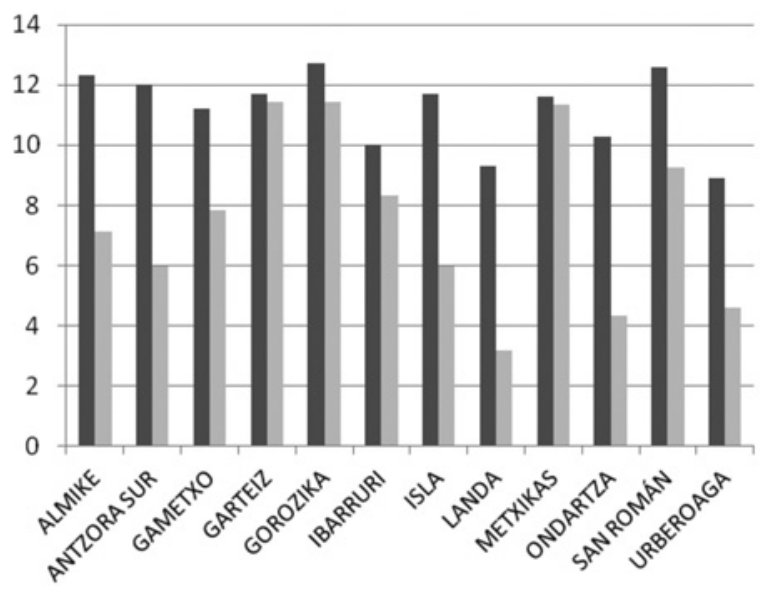

Fuente: elaboración propia. 
25 por NR. Este límite, si bien ha resultado muy insuficiente para proteger de manera eficaz el carácter y la integridad de los barrios de caseríos, de acuerdo con el trabajo de campo realizado impone cierto freno que aún permite la pervivencia de valores paisajísticos en un entorno que, comparativamente con otras áreas del País Vasco, sigue resultando privilegiado. De hecho, la demanda de parcelas para construir vivienda unifamiliar en los Núcleos Rurales se mantiene, incluso en un momento crítico para el mercado inmobiliario como el actual.

A día de hoy los barrios de caseríos con una buena calidad paisajística deben buscarse en los bordes de la Reseva de Urdaibai: en Garteiz, en Gorozika, en Metxikas; los NR centrales y aquellos que disponen de las vistas más valoradas socialmente han acelerado un proceso de deterioro en su paisaje que tampoco era nuevo. Pero es preciso matizar, porque las mayores pérdidas de calidad no derivan exclusivamente del mayor o menor desarrollo del proceso. En San Román, por ejemplo, se han construido 9 viviendas unifamiliares en un NR que cuenta con 12 caseríos preexistentes y, sin embargo, el impacto global es medio. Ya se señalaba más arriba que en este núcleo como en otros en los que la nueva vivienda pertenecía a familias con vínculos en el propio NR - frecuentemente hijos de propietarios de caseríos - la integración de la nueva vivienda resulta menos agresiva, las parcelas no se cercan con altos setos, incluso se mantienen los usos agrarios en una parte de las mismas... Sin embargo, el elevadísimo valor de las parcelas con vistas al mar o a la ría ha propiciado su venta a propietarios de alto poder adquisitivo. Nuevos residentes con necesidad de «bunkerizar» una viviendas que por sus volúmenes y estilo arquitectónico conectan peor con un barrio de caseríos.

La distribución de la nueva vivienda con respecto a la estructura espacial del caserío preexistente y las parcelas a éstos adscritas es pésima en todos los NR analizados, y si no alcanza valores más altos en algunos de ellos únicamente se debe a que el desarrollo del proceso es aún incipiente. De hecho, puede llegar incluso a perderse la condición de Núcleo Rural, cuando menos desde el punto de vista de la percepción; los barrios de Landa o Urberoaga se aproximan a pequeñas urbanizaciones que suman a su falta de identidad el desorden urbanístico.

En buena medida dicho desorden proviene del hecho de que las parcelas edificables deban contar con acceso directo a los viales, debiendo respetarse tanto el parcelario como los accesos preexistentes. Requisitos mediante los que la Ley del Suelo del País Vasco parece buscar una urbanización «blanda» de los NR, tratando de impedir que lleguen a perder su carácter de hábitat rural (Bilbao, 2007). Pero lo cierto es que tales exigencias se han mostrado claramente contraproducentes porque al agrupar la nueva vivienda en las parcelas adyacentes a los caminos resultan éstas últimas las más visibles y si, además, se cercan con altos setos el núcleo se fragmenta y sustrae del campo visual. Todo ello unido a la falta de adecuación de las nuevas construcciones en materia de volumen, forma, materiales, color... aspectos que el planeamiento municipal no ha podido controlar eficazmente, ha derivado en una clara pérdida de la integridad de los núcleos rurales.

No obstante, el aspecto quizá más importante es la pérdida del carácter propio de los barrios de caseríos como consecuencia de su disfuncionalidad en cuanto que espacios agrarios. En este sentido, la obligatoriedad de respetar el parcelario preexistente ha supuesto la sustracción de un volumen de tierras importante, quizá imprescindible para asegurar cierta viabilidad en cuanto que explotación agraria no ya del conjunto de caseríos de cada barrio sino al menos de alguno de ellos. La actual calidad paisajística de los NR está directamente 
relacionada con el aprovechamiento agrario de las tierras que tienen adscritas, aspecto que marca una diferencia cualitativa entre unos y otros. Son aquellos más excéntricos, con menores expectativas de construcción, como Garteiz, Ibarruri, Metxikas... en los que se mantiene el uso y cuidado de la parcelas, en tanto que en Isla, por ejemplo, la expectativa ha propiciado abandonos, dando lugar a un espacio que en determinados sectores recuerda los baldíos de las periferias urbanas antes que el privilegiado entorno de una Reserva de la Biosfera.

Fuera ya de los barrios de caseríos, sobre el conjunto de la cuenca de Urdaibai el impacto paisajístico que generan las nuevas construcciones no puede calificarse de gran impacto, es un impacto de baja intensidad. Vista desde perspectivas más amplias, la nueva vivienda parece diluirse en el hábitat disperso de la Reserva, que tiende a hacerse progresivamente más abigarrado, pero sin que hasta el momento parezca alcanzar niveles alarmantes en lo paisajístico, dado el volumen y tipología unifamiliar de la nueva vivienda que es posible construir sobre cada núcleo rural. Es quizá esa circunstancia la que ha llevado a minusvalorar este impacto frente a otro tipo de actuaciones claramente perturbadoras: nuevos viales, parques eólicos, canteras... No obstante, la calidad intrínseca de los NR se está viendo seriamente afectada. Es verdad que en algunos de ellos el nivel de partida tampoco era óptimo, que estaban ya afectados por procesos anteriores aunque de la misma índole. Pero tampoco esa puede ser una excusa para desestimar las consecuencias que la atípica figura de Núcleo Rural está contribuyendo a generalizar sobre todos los barrios de caseríos sin excepción, dentro y fuera de Urdaibai.

\section{CONCLUSIONES}

Sin duda el paisaje es dinámico y cambiante; no se trata de detener el tiempo y reconstruir el paisaje perdido, pero es preciso orientar la evolución del lugar porque determinará el paisaje futuro (Consejo de Europa, 2008). Tal orientación exige algo más que meras recomendaciones, cuando menos en el caso de los Núcleos Rurales del País Vasco. Si se vuelve sobre el contenido del artículo 81 del PRUG de Urdaibai, citado al inicio de este trabajo, puede observarse que se intuían claramente los parámetros generadores del impacto paisajístico derivado de la urbanización. Sin embargo, no se consideraron de relevancia suficiente como para establecer una normativa precisa, frente a otras áreas de la Reserva donde la presencia de valores naturalísticos indujo un control estricto.

Pareciera que dada su abundancia relativa, los barrios de caseríos que se constituyen en unidades expresivas del carácter y la identidad del paisaje vasco-atlántico, según reconocen tanto el PRUG como las propias DOT, no merecieran una salvaguarda real; o quizá simplemente se trate de la dificultad que entraña enfrentarse a la presión urbanística. En cualquier caso y dada la realidad de la pérdida paisajística a que se están viendo sometidos, se mida ésta como se mida, dar un paso adelante exige por parte de las autoridades públicas conocer las aspiraciones de la población respecto a esa parte del territorio y en relación con ellas arbitrar las iniciativas precisas para salvaguardar su carácter, si fuera el caso, y gestionar el cambio tal y como propugna la CEP.

En ese sentido, sería de gran interés contar con algún tipo de herramienta específica, quizá similar a la «Zona de Protección» contemplada por el Código de Urbanismo francés para los hábitats rurales de interés, aplicable al conjunto de los NR y desde la que se esta- 
blezcan medidas de control sobre los procesos que provocan la pérdida del carácter y la calidad de su paisaje. Una vez establecidos los factores generadores de impacto, es urgente buscar una mayor integración de las nuevas viviendas sobre los NR. No obstante, no parece suficiente limitarse a intervenir sobre los aspectos puramente formales; debe valorarse la propia oportunidad del Núcleo Rural en cuanto que figura urbanística, ya que mediatiza la funcionalidad futura del espacio rural. Se está asistiendo no sólo al deterioro del paisaje de caseríos, sino también a una suerte de privatización del mismo en cuanto que se destina a la ubicación de cierta vivienda particular.

\section{BIBLIOGRAFÍA}

AINZ IBARRONDO, M.J. (2001): El caserío vasco en el país de las industrias. Ministerio de Agricultura, Pesca y Alimentación, Serie Estudios, nº 147, 360 pp.

AINZ IBARRONDO, M.J., BILBAO URIBARRI, A., TORRES ELIZBURU R. (2011): «Dispersión urbana en el Suelo No Urbanizable del País Vasco: la distorsión del planeamiento en la Reserva de la Biosfera de Urdaibai». Estudios Geográficos, Vol. 72, n.271, 371-401.

BAESCHLIN, A. (1992): La arquitectura del caserío vasco. Eusko Ikaskuntza, $1^{\circ}$ ed. Canosa, Barcelona, 1930.

BILBAO URÍBARRI, A. (2007): «Los núcleos rurales en el País Vasco como precursores de la dispersión urbana. La Reserva de la Biosfera de Urdaibai. Ciudad y Territorio. Estudios Territoriales, XXXIX, 151, 83-102.

BRUSILOVSKY et al. (1996-97): Caracterización Urbanística de los Núcleos de Población Rurales en la Reserva de la Biosfera de Urdaibai. Informe inédito.

CONSEJO DE EUROPA (2000): Convención Europea del Paisaje. Congress of Local and Regional Authorities of Europe.

CONSEJO DE EUROPA (2008): Orientaciones para la aplicación del Convenio Europeo del Paisaje.

GOBIERNO VASCO (1993): Plan Rector de Uso y Gestión de la Reserva de la Biosfera de Urdaibai. BOPV, 235 de 7 de diciembre de 1993, págs. 10.810-10.949.

GOBIERNO VASCO (1997): Directrices de Ordenación Territorial. Departamento de Ordenación del Territorio y Medio Ambiente. Vitoria, $335 \mathrm{pp}$.

GOBIERNO VASCO (2003): Modificación del Plan Rector de Uso y Gestión de la Reserva de la Biosfera de Urdaibai. BOPV, 46 de 5 de marzo de 2003, págs. 3.383-3.386 y Anexo.

GOBIERNO VASCO (2005): Catálogo abierto de paisajes singulares y sobresalientes de la CAPV. Anteproyecto. Tomo II. Ordenación del Territorio y Medio Ambiente. Vitoria, 73 pp.

GOBIERNO VASCO (2012): Modificación de las Directrices de Ordenación Territorial. Departamento de Ordenación del Territorio y Medio Ambiente. Aprobación Inicial, Vitoria.

INSTITUTO DE ESTUDIOS TERRITORIALES DE BIZKAIA (2003): Análisis socioeconómico de la evolución del Urban Sprawl en el Territorio Histórico de Bizkaia. Bilbao, Diputación Foral de Bizkaia.

JIMÉNEZ OLIVENZA, Y. y PORCEL RODRÍGUEZ, L. (2008): «Metodología para el estudio evolutivo del paisaje: aplicación al espacio protegido de Sierra Nevada». Cuadernos Geográficos, 43 (2008-2), 151-179. 
LUGINBÜHL, Y. (2009): «Paisaje y calidad de vida». En: 1er Congreso, Paisaje e Infraestructuras. Sevilla, 53-65.

MATA, R. (2006): «Métodos de estudio del paisaje e instrumentos para su gestión. Consideraciones a partir de experiencias de planificación territorial». En El paisaje y la gestión del territorio Criterios paisajísticos en la ordenación del territorio y el urbanismo (Mata, R. y Tarroja, A., Coord.) Diputació de Barcelona-Universidad Internacional Menéndez Pelayo, 2006, 716, 199-239.

NOGUÉ, J. y SALA, P. (2008): «El Paisaje en la Ordenación del Territorio. Los catálogos de paisaje de Cataluña». Cuadernos Geográficos, 43 (2008-2), 69-98.

ORMAETXEA, O., SAÉNZ DE OLAZAGOITIA, A. \& IBISATE, A. (2008): «El efecto del proceso de urbanización difusa en la calidad paisajística de un espacio protegido». Cuadernos Geográficos, 43 (2008-2), 263-276.

PAQUETTE, S. y DOMON, G. (2003): «Changing ruralities, changing landscapes: exploring social recomposition using a multi-scale approach». Journal of Rural Studies, 19, 425-444.

TORRES ELIZBURU, R. (2014): La dispersión urbana en el País Vasco. Los patrones de la redistribución espacial de la población y nuevas realidades residenciales y urbanísticas, 1991-2010. Tesis doctoral, UPV/EHU http://hdl.handle.net/10810/13277.

SILVA PÉREZ, R. (2009): «Agricultura, paisaje y patrimonio territorial. Los paisajes de la agricultura vistos como patrimonio». Boletín de la Asociación de Geógrafos Españoles, 49, 309-334.

ZOIDO, F. (2002): «El paisaje y su utilidad para la Ordenación del Territorio». En: Paisaje y Ordenación del Territorio (Zoido, F. y Venegas, C., Coords.) Junta de Andalucía. Consejería de Obras Públicas y Transportes. Fundación Duques de Soria, 21-32. 
